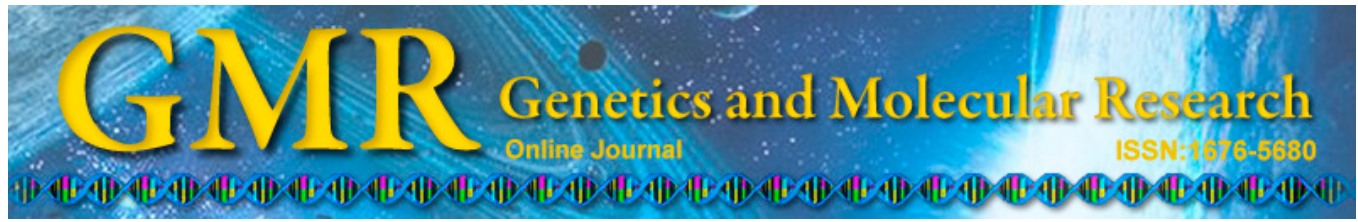

\title{
Identification of genes involved in regulatory mechanism of pigments in broiler chickens
}

\author{
T.M. Tarique ${ }^{1,2}$, S. Yang ${ }^{1}$, Z. Mohsina ${ }^{1}$, J. Qiu ${ }^{1}$, Z. Yan ${ }^{1}$, \\ G. Chen ${ }^{1}$ and A. Chen ${ }^{1}$ \\ ${ }^{1}$ State Key Laboratory of Agro-Product Quality and Safety, \\ Institute of Quality Standards and Testing Technology for Agro-Products, \\ Chinese Academy of Agricultural Sciences, Beijing, China \\ ${ }^{2}$ Department of Agricultural Sciences, Faculty of Sciences, \\ Allama Iqbal Open University, Islamabad, Pakistan \\ Corresponding authors: T.M. Tarique / S.M. Yang \\ E-mail: Tarique_tunio@hotmail.com / yangshumingcaas@sina.com
}

Genet. Mol. Res. 13 (3): 7201-7216 (2014)

Received January 2, 2014

Accepted May 15, 2014

Published September 5, 2014

DOI http://dx.doi.org/10.4238/2014.September.5.6

\begin{abstract}
Chicken is an important model organism that unites the evolutionary gap between mammals and other vertebrates and provide major source of protein from meat and eggs for all over the world population. However, specific genes underlying the regulatory mechanism of broiler pigmentation have not yet been determined. In order to better understand the genes involved in the mechanism of pigmentation in the muscle tissues of broilers, the Affymetrix microarray hybridization experiment platform was used to identify gene expression profiles at 7 weeks of age. Broilers fed canthaxanthin, natural lutein, and orangeII pigments $(100 \mathrm{mg} / \mathrm{kg})$ were used to explore gene expression profiles). Our data showed that the 7th week of age was a very important phase with regard to gene expression profiles. We identified a number of differentially expressed genes; in canthaxanthin, natural lutein, and orangeII, there were 54 (32 upregulated and 22 downregulated), 23 (15 upregulated and 8 downregulated), and 7 (5 upregulated and 2 downregulated) known genes, respectively. Our
\end{abstract}


data indicate that the numbers of differentially expressed genes were more upregulated than downregulated, and several genes showed conserved signaling to previously known functions. Thus, functional characterization of differentially expressed genes revealed several categories that are involved in important biological processes, including pigmentation, growth, molecular mechanisms, fat metabolism, cell proliferation, immune response, lipid metabolism, and protein synthesis and degradation. The results of the present study demonstrate that the genes associated with canthaxanthin, natural lutein, and orangeII are key regulatory genes that control the regulatory mechanisms of pigmentation.

Key words: Broiler pigment; Expressed genes; Microarrays; Regulation mechanism of pigments

\section{INTRODUCTION}

In recent years, China has become one of the world's fastest growing economies, with growth rates in the range of 5-15\% annually. Poultry farms in China have made a significant contribution towards the enhancement of food production strategies. Thus, in China, the subject of pigmentation and factors affecting pigmentation are broad (Tarique et al., 2013). The chicken is an important non-mammalian model organism that unites the evolutionary gap between mammals and other vertebrates; it also provides a major source of protein from meat and eggs worldwide. Pigmentation is one of the most important characteristics that determines acceptance by consumers and the quality of chickens before purchase or consumption in many countries (Castañeda et al., 2005; Tarique et al., 2013). The color of the skin, flesh, and egg yolk of chickens play key roles in different parts of the world based on consumer demands (Fletcher, 1999). The majority of consumers prefer to buy golden and red chickens because they believe that golden and red pigmentation is often associated with healthy and fresh chicken (Sunde, 1992). Carcasses that do not have the desired coloration are rejected by consumers. In addition, pigments are used as feed additives to enhance the color of broiler and aquaculture animal products.

The study of animal pigmentation has been flourishing greatly with the characterization of different pigment molecules, the identification of their function and cellular locations, and the definition of their biosynthetic pathways (Tyczkowski and Hamilton, 1986), which has engaged many chemists, biochemists, physiologists, cell biologists, and geneticists. In recent years, sequencing of the chicken genome (Wallis et al., 2004; Wong et al., 2004) and advances in microarray technology now make it possible for researchers to evaluate the expression of thousands of genes at the same time (Li et al., 2008). Gene expression microarray has become a leading analytical technology in chicken genomic research and is expected to play a crucial role in the emerging poultry field. Furthermore, these studies have provided information on global gene expression in chickens. Microarray analysis has proven useful as a flourishing approach for the classification of functional genes in several model organisms (e.g., humans, 
rodents, and fruit flies) (Cogburn et al., 2003) and is considered as a powerful tool for visualizing the molecular mechanism that governs complex biological responses; it is also used in gene expression analysis (van Hal et al., 2000). The technology is primarily used to assess the expression of different genes, search for new genes, the molecular diagnosis of disease, gene mutation and polymorphism analyses, and drug development in order to analyze and ascertain the specificity of these comprehensive gene expressions on large scale (Nakachi et al., 2008). The yellow skin allele in the chicken allows deposition of pigments in the skin and explains why most chickens have yellow legs and coloration. There is a growing need for poultry nutritionists to conduct regulatory research amidst a large number of new challenges to respond to consumer demand, regulatory laboratories, agencies, and food industries. However, to our knowledge, prior microarray studies have not investigated the relationship between gene expression and pigmentation. Thus, the objective of the present study was to identify genes involved in the regulatory mechanism of pigmentation in broiler chickens. The Affymetrix microarray hybridization experiment platform was utilized to identify gene expression profiles at 7 weeks of age and classify the different genes by Gene Ontology (GO) to understand the regulatory mechanism of pigmentation. In addition, candidate genes (or cluster of genes) were recognized as key regulatory genes.

\section{MATERIAL AND METHODS}

\section{Broilers and housing}

The present study was conducted at the Animal Sciences Institute in accordance with recommendations and the approval of the Animal Care Committee of the Institute of Quality Standard and Testing Technology for Agro Products, Chinese Academy of Agricultural Sciences (IQSTAP-CAAS). Arbor Acres one-day-old broiler chicks $(\mathrm{N}=300$ males and 300 females) were acquired from Beijing Poultry Breeding Co., Ltd. (Beijing, China). The chicks were housed in a room with forced ventilation, automated heating, and a programmable fluorescent lighting system. All birds had access to water and the experimental diets ad libitum. Maximum and minimum temperatures were recorded daily. The health statuses of birds were monitored twice daily to remove deceased birds and identify possible health concerns. Ventpecking and other abnormal behaviors were not observed in any of the groups. The experiment was conducted over a 7-week period.

\section{Experimental diets and treatments}

All diets were formulated based on the recommendations of the National Research Council (1994). From 0-21 days of age, birds received a starter feed containing $2990 \mathrm{kcal} / \mathrm{kg}$ of metabolizable energy (ME) and 21.63\% crude protein (CP); from 21-49 days they were fed a finisher diet of $3120 \mathrm{kcal} / \mathrm{kg} \mathrm{ME}$ and $18.58 \% \mathrm{CP}$. The compositions of the basal experimental diets are shown in Table 1. The experimental design was prepared to study the identification of genes involved in the regulatory mechanism of pigmentation. Thus, 3 dietary treatments were administered as follows: $\mathrm{T}-1$, basal diet plus natural lutein $(100 \mathrm{mg} / \mathrm{kg})$; $\mathrm{T}-2$, basal diet plus canthaxanthin $(100 \mathrm{mg} / \mathrm{kg})$; and T-3, basal diet plus orangeII $(100 \mathrm{mg} / \mathrm{kg})$. A control group of birds received a diet that did not contain pigment additives. 


\begin{tabular}{|c|c|c|}
\hline \multirow[t]{2}{*}{ Ingredient (\%) } & \multicolumn{2}{|c|}{ Basal diets } \\
\hline & $\begin{array}{c}\text { Starter } \\
\text { (1-21 days) }\end{array}$ & $\begin{array}{c}\text { Finisher } \\
\text { (22-49 days) }\end{array}$ \\
\hline Wheat & 36.2 & 46 \\
\hline Soybean meal & 34.15 & 23.59 \\
\hline Maize & 20 & 20 \\
\hline Calcium phosphate & 1.95 & 1.75 \\
\hline Limestone & 1 & 0.85 \\
\hline $\mathrm{NaCl}$ & 0.3 & 0.3 \\
\hline Lysine & 0.15 & 0.28 \\
\hline Methionine & 0.2 & 0.18 \\
\hline Premix & 1 & 1 \\
\hline Soy bean oil & 5 & 6 \\
\hline Xylanase & 0.05 & 0.05 \\
\hline \multicolumn{3}{|c|}{ Calculated nutrient values } \\
\hline $\mathrm{ME}(\mathrm{kcal} / \mathrm{kg})$ & 2990 & 3120 \\
\hline $\mathrm{CP}$ & 21.63 & 18.58 \\
\hline Calcium & 0.99 & 0.87 \\
\hline Available P & 0.47 & 0.43 \\
\hline Lysine & 1.19 & 1.03 \\
\hline Methionine & 0.52 & 0.47 \\
\hline Methionine+cystine & 0.71 & 0.67 \\
\hline
\end{tabular}

Broiler 1\% premix supplied the following amount of vitamins and trace elements of nutritional requirements (per kilogram of feed): Mn 90 mg; Zn 50 mg; Fe 90 mg; Cu 10 mg; I 0.4 mg; Se 0.2 mg; VA 5000 IU; VD3 500 IU; VE $10 \mathrm{IU}$; VK $0.5 \mathrm{mg}$; VB1 $1.5 \mathrm{mg}$; VB2 $6.0 \mathrm{mg}$; panthothenic acid $12 \mathrm{mg}$; niacin $35 \mathrm{mg}$; VB6 $6.0 \mathrm{mg}$; folic acid 0.8 $\mathrm{mg}$; VB12 $0.01 \mathrm{mg}$; and biotin $0.18 \mathrm{mg}$.

\section{Tissue sampling collection and preparation}

Upon termination of the experiment (i.e., week 7), the birds were slaughtered and the breast muscles were isolated to avoid contamination and minimize nuclease activity. Tissue samples were immediately frozen in liquid nitrogen, which took no longer than 5 min. The samples were then stored at $-80^{\circ} \mathrm{C}$ until analysis. The tissue samples were collected based on the following: group A, birds fed $100 \mathrm{mg} / \mathrm{kg}$ canthaxanthin; B, birds fed $100 \mathrm{mg} / \mathrm{kg}$ natural lutein; C, birds fed $100 \mathrm{mg} / \mathrm{kg}$ orangeII; and D, control animals for each muscle tissue.

\section{RNA isolation}

Total RNA was isolated from treated and untreated breast muscle samples in triplicate using the TRIzol reagent (Invitrogen Life Technologies, Cat\# 155960-018) following manufacturer protocols. The extracted RNA quality and concentration was then assessed by the $\mathrm{A}_{260}: \mathrm{A}_{280}$ ratio and quantified on a NanoDrop spectrophotometer (ND-2000).

\section{Complementary DNA (cDNA) synthesis}

cDNA synthesis was prepared and purified by oligo(dT) primed reverse transcription using a Poly-A RNA Control kit (Affymetrix, P/N900433 Capital Bio China). The GeneChip $^{\circledR}$ Affymetrix Chicken Genome Array was used in the current study; every 3 points represented 3 repeats of a single gene. 


\section{Synthesis of cRNA labeled with biotin and fragmentation}

Biotinylated dNTPs were incorporated into the generated cRNA during transcription using the MessageAmpTM II-Biotin RNA Amplification Kit (Ambion, \#17910). The RNA products were fragmented into strands of $\leq 200$ bp using a $5 \mathrm{X}$ fragmented buffer.

\section{Hybridization, washing, and staining}

Before hybridization, microarrays were prehybridized in $300 \mu \mathrm{L} 1 \mathrm{X}$ hybridization buffer at $45^{\circ} \mathrm{C}$ for $10 \mathrm{~min}$; the microarrays were then incubated for $16 \mathrm{~h}$ at $45^{\circ} \mathrm{C}$ with constant rotation $(60 \mathrm{rpm})$ in hybridization oven 640 (Affymetrix) using the Hybridization Control Kit (Affymetrix, P/N 900457). After hybridization, the microarrays were washed on a fluidics station (Fluidics Station 450, Affymetrix). Microarrays were stained with stain cocktail 1 and then subjected to $10 \times 4$ wash cycles to complete the staining process.

\section{Microarray scanning and data analysis}

The microarrays were scanned using the GeneChip ${ }^{\circledR}$ Scanner 3000 (Affymetrix). Raw data sets were normalized to total fluorescence, which represented the total amount of cRNA hybridized to a microarray, using the Affymetrix ${ }^{\circledR}$ GeneChip ${ }^{\circledR}$ Operating Software v1.4. Datasets were excluded if the absolute call (Abs call) was absent or marginal according to the detection $\mathrm{P}$ value in all microarrays. Only the expression transcripts (the Abs Call was present) were used for further analysis. Differentially expressed genes were identified from standardized data using the significance analysis of microarrays (SAM) algorithm. According to the SAM algorithm, genes were identified as differentially expressed on the basis of expression differences between the samples and the consistency of those differences. A gene was deemed significant if a fold change value (FC) surpassed a certain threshold. If $\mathrm{FC} \geq 2.0$, genes were upregulated; if $\mathrm{FC} \leq 0.5$, genes were downregulated. Clustering was achieved using average linkage clustering. The clustering image was displayed in tree view. Gene functions and specific biological pathways were analyzed via molecular comments platform (MAS 3.0).

\section{RESULTS}

\section{Cluster dendrogram of differentially expressed genes}

The cluster analysis of all microarrays was performed (Figure 1) using the Cluster 3.0 software. The results revealed the expression of the individual treatment profiles, which were illustrated in columns (one column for each sample). Moreover, accuracy of the expression data was supported by comparing the information obtained in the microarray dataset, which helped to explore the novel genes involved in the regulation of pigmentation. The color represents the expression of the gene. Red and green represent high and low levels of expression, respectively. 


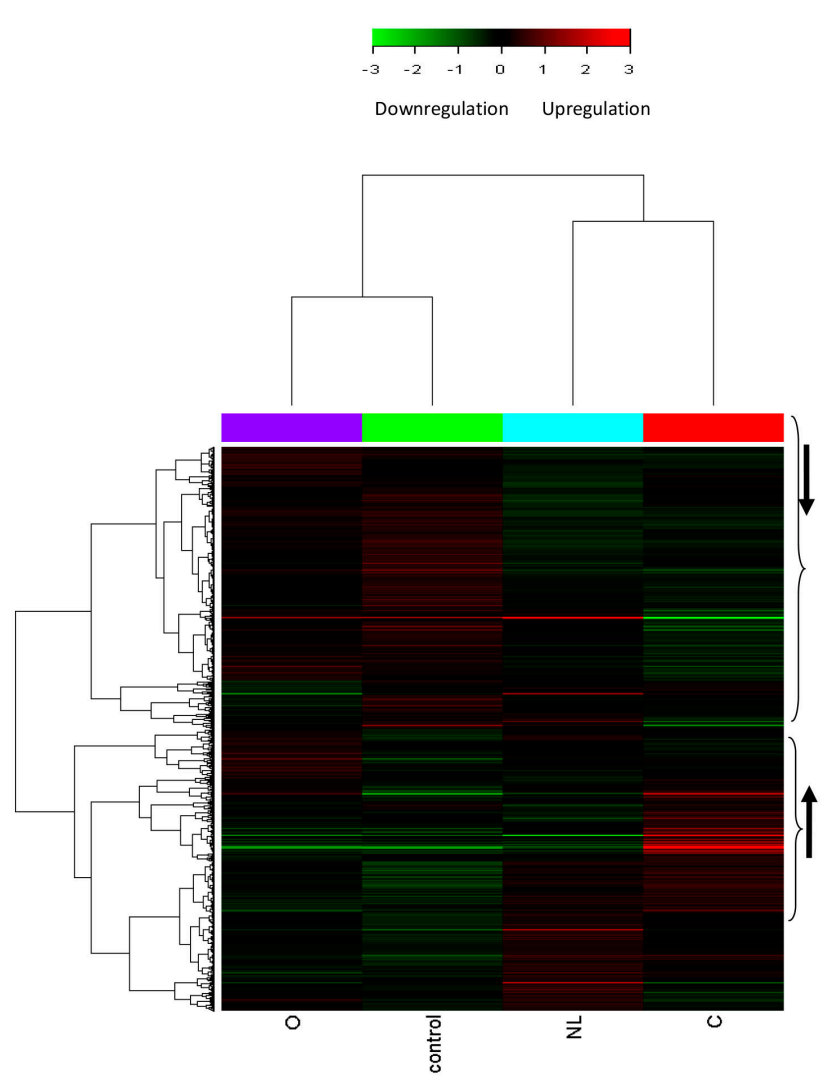

Figure 1. Cluster analysis of microarray expression profiles of up- and downregulated gene expression levels. Columns marked with red at the top represent samples from broilers fed canthaxanthin (C); columns marked with turquoise at the top represent samples from broilers fed natural lutein (NL); columns marked bright green at the top represent samples from the controls; and columns marked with purple at top represent samples from broilers fed orange-II $(\mathrm{O})$.

\section{Screening of differentially expressed key genes of canthaxanthin, natural lutein, and orange II pigments}

To identify potential candidate genes underlying the molecular mechanisms involved in the above phenomena in response to different treatments, we used the Affymetrix Chicken Genome Array to investigate the gene expression profile of broiler pigmentation at 7 weeks of age. For categorization, the two-class SAM analysis was performed on the log transformed data matrix. This led to the identification of a total of 1120 differentially expressed genes related to canthaxanthin; 54 (32 upregulated and 22 downregulated) were known genes, including PENK, TTN, MYL10, KRT75, PDK4, ACTN2, MYOT, KRT9, HBA2, TPM1, and ABLIM2 (Table 2; Figure 2). With regard to natural lutein, of the total 1101 differentially expressed genes, 23 (15 upregulated and 8 downregulated) were known genes, including SERPINB2, CSTA, PTN, FGFBP1, RAMP2, COLA42, HBA1, and TPM3 (Table 3; Figure 2). With regard to orangeII, a total of 313 differentially expressed genes were identified; 7 (5 upregulated 
and 2 downregulated) were known genes, including PENK, $H B A 1, M T 3, H B A 2$, and $H B G 1$ (Table 4; Figure 2). Thus, the $P E N K$ and $H B A 1$ genes were common among all 3 treatments.

Table 2. List of differentially expressed genes associated with broiler muscles as determined by the Affymetrix microarray platform at 7 weeks of age for canthaxanthin-fed vs control broilers.

\begin{tabular}{|c|c|c|c|c|}
\hline Affy ID & Gene title & Gene symbol & Ratio & Regulation \\
\hline Gga.11430.1.S1_at & Proenkephalin & PENK & 3.1019 & Up \\
\hline Gga.13194.1.S1_at & Myosin, light chain 10 , regulatory & MYL10 & 14.5182 & Up \\
\hline Gga.16444.1.S1_at & Pyruvate dehydrogenase kinase, isozyme 4 & PDK4 & 2.3987 & Up \\
\hline Gga.17467.1.S1_s_at & Titin & $\begin{array}{l}\text { TTN } \\
\text { LOC771699 }\end{array}$ & 146.3781 & Up \\
\hline Gga.1755.3.S1_a_at & Similar to nebulin /// nebulin & NEB & 130.4435 & Up \\
\hline Gga.18919.1.S1_a_at & $\begin{array}{l}\text { Min alpha-trop /// similar to tropomyosin alpha-3 chain } \\
\text { (Tropomyosin-3) (Tropomyosin gamma) (hTM5) }\end{array}$ & $\begin{array}{l}\text { LOC } 396429 \\
\text { LOC } 770103\end{array}$ & 64.6898 & Up \\
\hline Gga.19188.1.S1_at & Kelch repeat and BTB (POZ) domain containing 10 & KBTBD10 & 199.4032 & Up \\
\hline Gga.19481.1.S1_at & Titin & TTN & 323.9204 & Up \\
\hline Gga.1960.2.S1_àat & Myoglobin & MB & 116.0291 & Up \\
\hline Gga.2975.1.S1_at & Potassium channel tetramerization domain containing 1 & KCTD1 & 2.6019 & Up \\
\hline Gga.3391.1.S1_at & Keratin 15 & KRT15 & 2.0951 & Up \\
\hline Gga.3908.1.S1_at & Transgelin & TAGLN & 2.0951 & Up \\
\hline Gga.4053.1.S1_at & Eukaryotic translation elongation factor 1 alpha 2 & EEF1A2 & 4.369 & Up \\
\hline Gga.4841.2.S1_a_at & Similar to KIAA0613 protein & LOC423610 & 197.1483 & Up \\
\hline Gga.4843.2.S1_a_at & Actinin, alpha 2 & ACTN2 & 33.3318 & Up \\
\hline Gga.6252.1.S1_at & Transmembrane protein $16 \mathrm{~A}$ & TMEM16A & 3.7478 & Up \\
\hline Gga.6482.1.S1_at & $\begin{array}{l}\text { Feather keratin } \mathrm{I} / / / \text { similar to Feather keratin I } \\
\text { (Keratin gene } \mathrm{C} \text { protein) }\end{array}$ & $\mathrm{F}-\mathrm{KER} / / /$ & 12.5551 & Up \\
\hline Gga.6558.1.S1_at & Similar to Feather keratin I (Keratin gene C protein) (F-ker) & LOC769121 & 10.4686 & Up \\
\hline Gga.6778.2.S1_at & Similar to Scale keratin (S-ker) (sKer) & LOC426912 & 2.2065 & Up \\
\hline Gga.6898.1.S1_at & Similar to feather keratin /// similar to feather keratin /// & LOC425854 /// & 23.7644 & Up \\
\hline Gga.750.1.S1_at & Myogenic differentiation 1 & MYOD1 & 104.8083 & Up \\
\hline Gga.8362.1.S1__at & Myozenin 2 & MYOZ2 & 258.0344 & Up \\
\hline Gga.866.1.S1_at & Collagen, type XVII, alpha 1 & COL17A1 & 2.1105 & $\mathrm{Up}$ \\
\hline Gga.8960.2.S1_at & Similar to Feather keratin I (Keratin gene C protein) (F-ker) & LOC426916 & 8.8784 & $\mathrm{Up}$ \\
\hline Gga.9462.1.S1_at & Myotilin & MYOT & 150.7302 & Up \\
\hline GgaAffx.20709.1.S1_s_at & BTB (POZ) domain containing 1 & BTBD1 & 2.1159 & Up \\
\hline GgaAffx.21581.1.S1_s_at & Chemokine (C-X-C motif) ligand 14 & CXCL14 & 5.2755 & Up \\
\hline GgaAffx.24000.1.S1_at & Desmoplakin & DSP & 2.284 & Up \\
\hline GgaAffx.26023.2.S1_at & Keratin 9 & KRT9 & 2.2643 & $\mathrm{Up}$ \\
\hline GgaAffx.26023.5.S1_s_at & Keratin 15 & KRT15 & 2.8707 & Up \\
\hline Gga.4196.1.S1_a_at & Actin binding LIM protein family, member 2 & ABLIM2 & 6.4305 & Up \\
\hline GgaAffx. $3525 . \overline{1} \cdot \overline{\mathrm{S}} 1$ at & Coagulation factor III (thromboplastin, tissue factor) & F3 & 2.0328 & $\mathrm{Up}$ \\
\hline GgaAffx.3568.1.S1_at & Cysteine-rich secretory protein LCCL domain containing 2 & CRISPLD2 & 0.4808 & Down \\
\hline Gga.17971.1.S1_s_āt & Protein phosphatase 1 , regulatory (inhibitor) subunit $12 \mathrm{~A}$ & RCJMB04_22k13 & 0.3918 & Down \\
\hline Gga.2830.1.S1_at & Hypothetical protein LOC776660 & LOC $7766 \overline{60}$ & 0.4164 & Down \\
\hline Gga.2902.1.S1_a_at & Hemoglobin, alpha 1 & HBA1 & 0.112 & Down \\
\hline Gga.3030.1.S1_at & Retinol saturase (all-trans-retinol 13,14-reductase) & RETSAT & 0.4494 & Down \\
\hline Gga.3159.1.S1_a_at & Protein phosphatase 1 , regulatory (inhibitor) subunit $12 \mathrm{~A}$ & RCJMB04_22k13 & 0.373 & Down \\
\hline Gga.4052.1.S1_at & Myosin, light chain 9 , regulatory & MYL9 & 0.4818 & Down \\
\hline Gga.4108.1.S2 at & Tropomyosin 1 (alpha) & TPM1 & 0.4187 & Down \\
\hline Gga.4110.12.S1_a_at & Immunoglobulin lambda-like polypeptide 1 & IGLL1 & 0.4387 & Down \\
\hline Gga.4128.3.S1_a_at & Tensin 1 & TNS1 & 0.4394 & Down \\
\hline Gga.4306.1.S1_at & Desmuslin & $\mathrm{DMN}$ & 0.4453 & Down \\
\hline Gga.4581.2.S1_at & BCL2-associated athanogene 2 & BAG2 & 0.4021 & Down \\
\hline Gga.481.1.S1_at & Fibromodulin & FMOD & 0.3985 & Down \\
\hline Gga.4975.5.S1_x_at & Tropomyosin 3 & TPM3 & 0.3817 & Down \\
\hline Gga.4981.1.S1_s_at & Hemoglobin, gamma A /// hemoglobin, gamma G & HBG1 /// HBG2 & 0.3042 & Down \\
\hline Gga.4982.1.S1_at & Aldolase A & LOC395492 & 0.4848 & Down \\
\hline Gga.4988.2.S1_a_at & Caldesmon 1 & CALD1 & 0.4603 & Down \\
\hline Gga.693.1.S1_at & Cysteine and glycine-rich protein 1 & CSRP1 & 0.446 & Down \\
\hline Gga.7442.1.S1_at & Prostaglandin E receptor 3 (subtype EP3) & PTGER3 & 0.3971 & Down \\
\hline Gga.9713.2.S1_a_at & Histidine triad nucleotide binding protein $\mathrm{W}$ & HINTW & 0.0027 & Down \\
\hline Gga.644.1.S1_at & Actin, gamma 2 , smooth muscle, enteric & ACTG2 & 0.4089 & Down \\
\hline
\end{tabular}




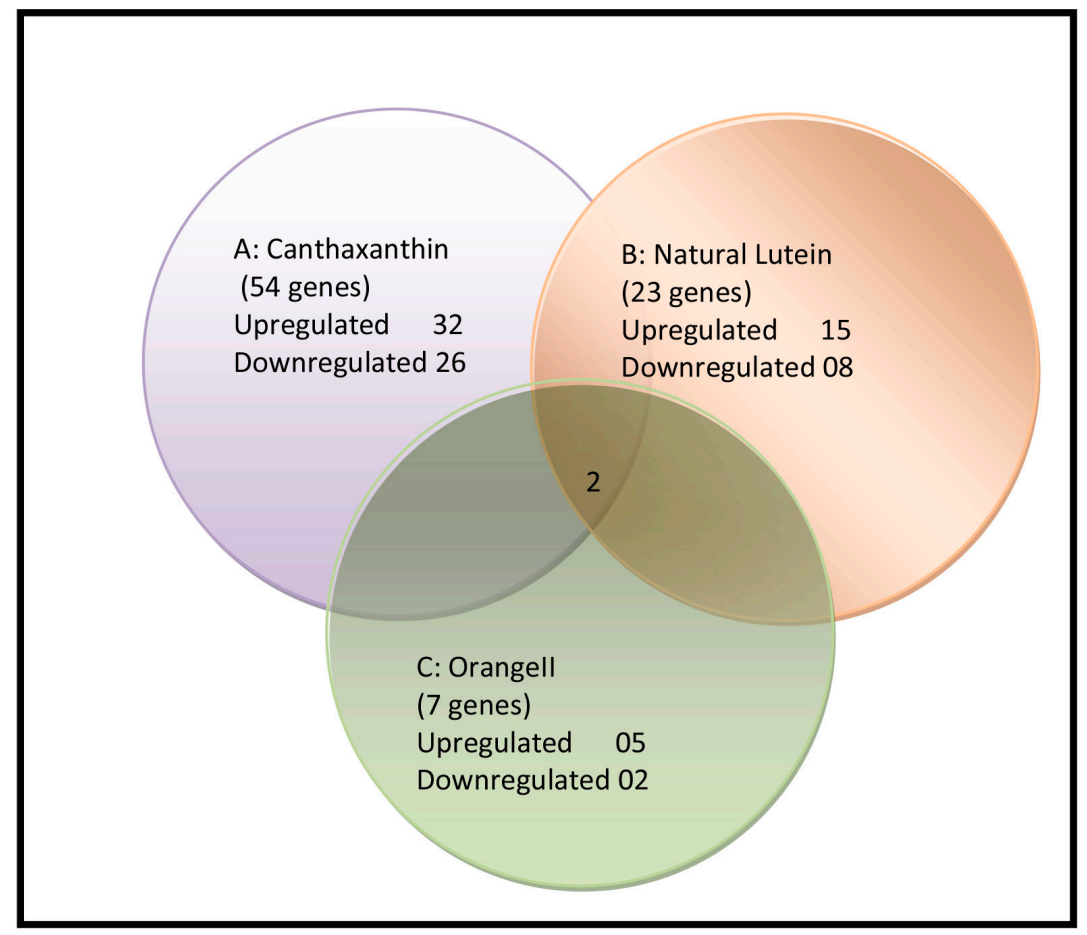

Figure 2. Venn diagram showing the numbers of known genes that were differentially expressed in the breast muscles between the different treatments.

Table 3. List of differentially expressed genes associated with broiler muscles as determined by the Affiymetrix microarray platform at 7 weeks of age for broilers fed natural lutein $v s$ control group.

\begin{tabular}{|c|c|c|c|c|}
\hline Affy ID & Gene title & Gene symbol & Ratio & Regulation \\
\hline Gga.10034.1.S1_at & Serpin peptidase inhibitor, clade B (ovalbumin), member 2 & SERPINB2 & 2.3226 & Up \\
\hline Gga.10344.1.S1_at & $\begin{array}{l}\text { Elongation of very long chain fatty acids } \\
\text { (FEN1/Elo2, SUR4/Elo3, yeast)-like } 4\end{array}$ & ELOVL4 & 2.0734 & $\mathrm{Up}$ \\
\hline Gga.10746.1.S1_at & Hypothetical protein LOC769486 & LOC769486 & 2.9469 & Up \\
\hline Gga.11430.1.S1_at & Proenkephalin & PENK & 4.3081 & $\mathrm{Up}$ \\
\hline Gga.11456.1.S1_at & Cystatin A (stefin A) & CSTA & 2.6501 & Up \\
\hline Gga.1479.1.S1_at & Pleiotrophin & PTN & 2.9773 & $\mathrm{Up}$ \\
\hline Gga.2876.2.S1_x_at & Vav 3 oncogene & VAV3 & 2.0305 & Up \\
\hline Gga.2982.1.S1_at & Cadherin 1, type 1, E-cadherin (epithelial) & $\mathrm{CDH} 1$ & 2.1311 & Up \\
\hline Gga.3149.1.S1_at & Keratin & LOC395095 & 2.5724 & Up \\
\hline Gga.5589.1.S1_at & Beta-keratin & LOC408038 & 4.6402 & Up \\
\hline Gga.8140.1.S1_at & Protein tyrosine phosphatase, receptor type, F & FGFBP1 & 2.1316 & $\mathrm{Up}$ \\
\hline Gga.844.1.S1 at & Keratin & LOC396479 & 2.7672 & Up \\
\hline Gga.8960.2.S1_at & Similar to feather keratin I (keratin gene C protein) (F-ker) & LOC426916 & 8.3626 & Up \\
\hline GgaAffx.26023.2.S1 at & Keratin 9 & KRT9 & 2.4396 & $\mathrm{Up}$ \\
\hline GgaAffx.26023.5.S1_s at & Keratin 15 & KRT15 & 2.1826 & Up \\
\hline Gga.12104.1.S1_at & Receptor (G protein-coupled) activity modifying protein 2 & RAMP2 & 0.4751 & Down \\
\hline Gga.19409.1.S1_s at & Collagen, type IV, alpha 2 & COL4A2 & 0.4662 & Down \\
\hline Gga.2909.1.S1_a at & Hemoglobin, alpha 1 & HBA1 & 0.2004 & Down \\
\hline Gga.3159.1.S1_a_at & Protein phosphatase 1 , regulatory (inhibitor) subunit $12 \mathrm{~A}$ & RCJMB04_22k13 & 0.4843 & Down \\
\hline Gga.4581.2.S1_at & BCL2-associated athanogene 2 & BAG2 & 0.4810 & Down \\
\hline Gga.4975.5.S1_x at & Tropomyosin 3 & TPM3 & 0.4107 & Down \\
\hline GgaAffx.11543.1.S1 s at & Phosphorylase, glycogen; brain & RCJMB04 2f16 & 0.4257 & Down \\
\hline GgaAffx.23003.1.S1_at & Actin-associated protein palladin & LOC 422430 & 0.3716 & Down \\
\hline
\end{tabular}


Table 4. List of differentially expressed genes associated with broiler muscles as determined by the Affymetrix microarray platform at 7 weeks of age for broilers fed orangeII vs control.

\begin{tabular}{|c|c|c|c|c|}
\hline Affy ID & Gene title & Gene symbol & Ratio & Regulation \\
\hline Gga.11430.1.S1 at & Proenkephalin & ENK & 6.8793 & Up \\
\hline Gga.3149.1.S1_at & Keratin & LOC395095 & 3.3342 & Up \\
\hline Gga.6264.1.S1_at & Similar to Feather keratin I (Keratin gene C protein) (F-ker) & LOC418813 & 5.4334 & Up \\
\hline GgaAffx.9262.1.S1_at & Metallothionein 3 & MT3 & 2.0066 & Up \\
\hline Gga.2909.1.S1_a_at & Hemoglobin, alpha 1 & HBA1 & 0.3741 & Down \\
\hline Gga.2902.1.S1_a_at & Hemoglobin, alpha 2 & HBA2 & 0.1358 & Down \\
\hline Gga.4981.1.S1_s_at & Hemoglobin, gamma A /// hemoglobin, gamma G & HBG1 /// HBG2 & 0.3598 & Down \\
\hline
\end{tabular}

\section{Pathway analysis of differentially expressed genes}

In order to understand the biological significance of the differential expression of the common up- and downregulated genes, differentially expressed genes were subjected to biological pathway analysis. Gene functions and biological pathways were analyzed using the Kyoto Encyclopedia of Genes and Genomes (KEGG) database by MAS.3.0. The results showed that there were significant differences between the differentially expressed genes of the canthaxanthin calcium signal pathway, drug metabolism, caffeine metabolism, purine metabolism, retinol metabolism, and MAPK signaling pathway (Figure 3). Differentially expressed genes of natural lutein were mainly involved in riboflavin metabolism, methionine metabolism, vitamin B6 metabolism, apoptosis, fatty acid metabolism, and thiamine metabolism (Figure 4). The differentially expressed genes of orangeII were related to glycolysis/ gluconeogenesis, keratan sulfate biosynthesis, and steroid biosynthesis (Figure 5).

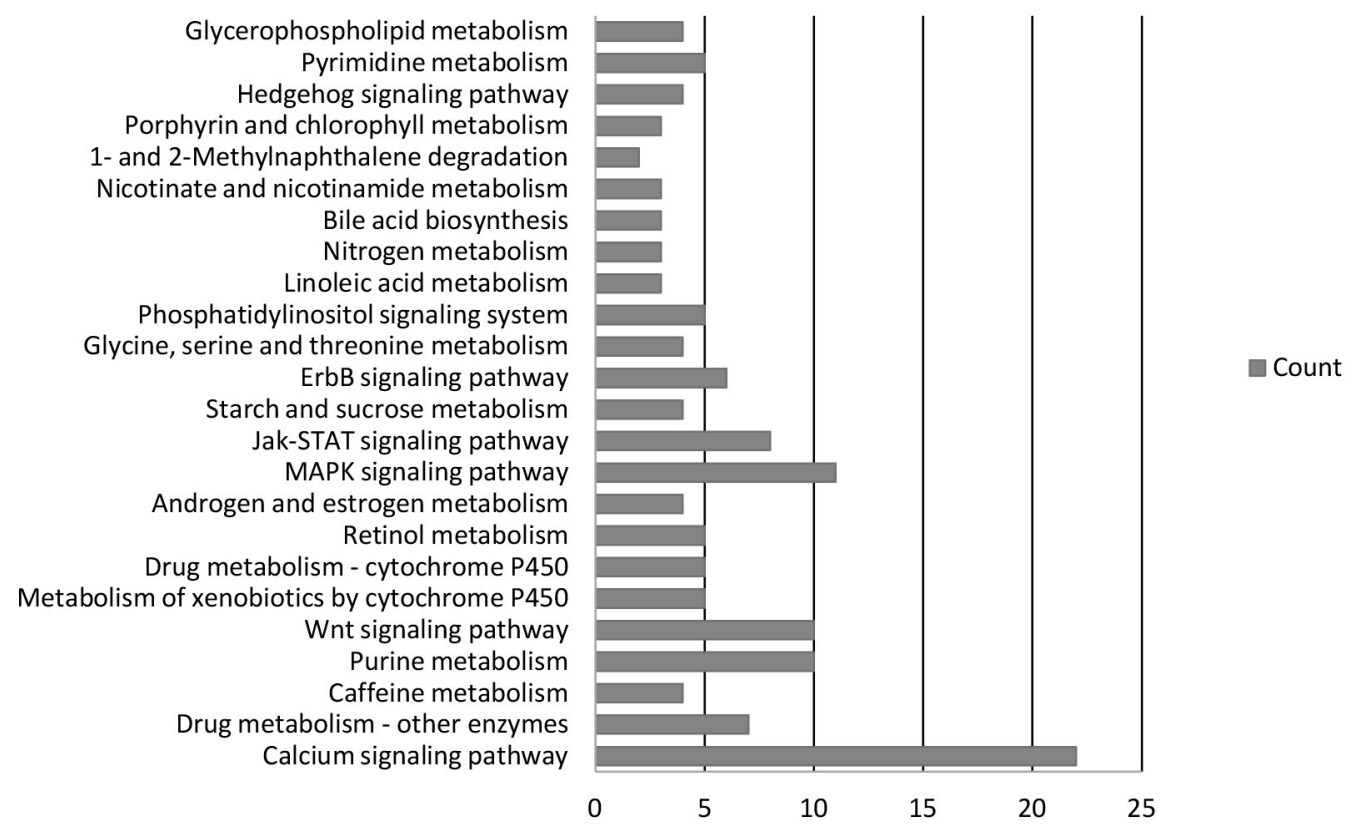

Figure 3. Pathway of differentially expressed genes in canthaxanthin-fed (count is the number of genes in a single pathway). 


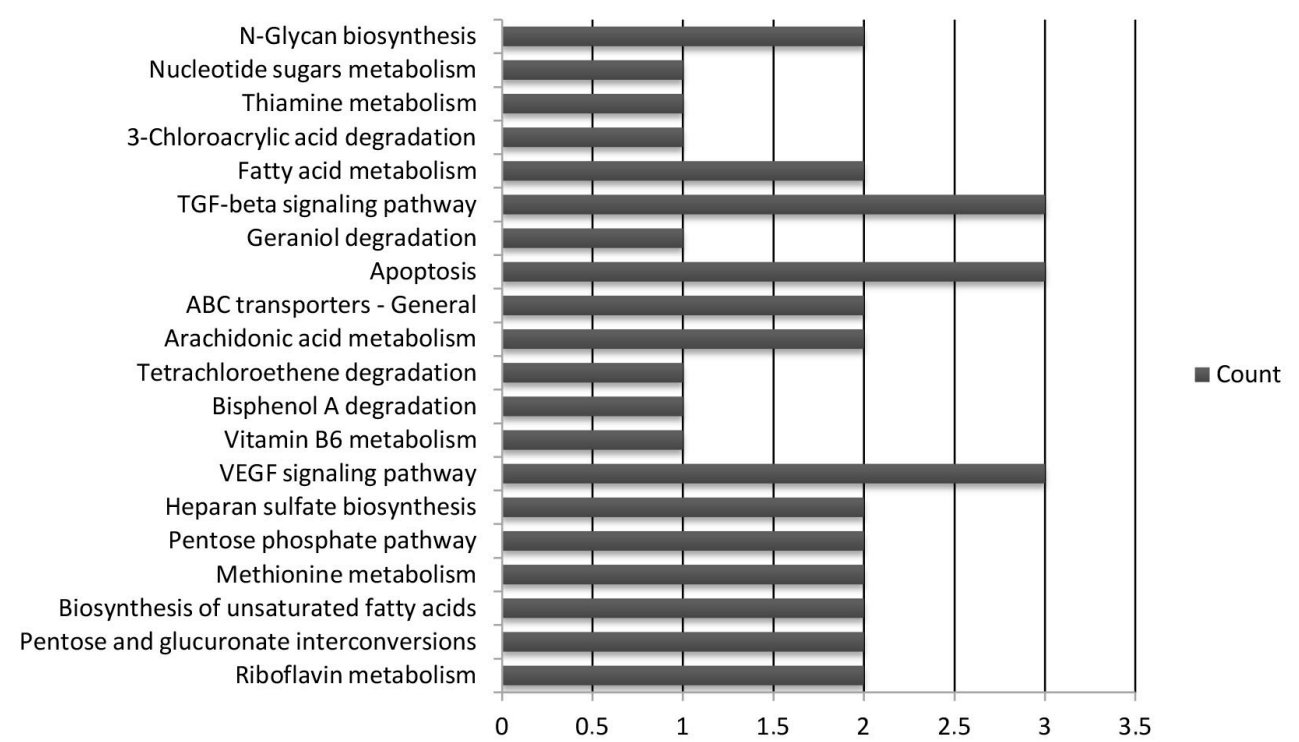

Figure 4. Pathway of differentially expressed genes in broilers fed natural lutein. Count is the number of genes in a single pathway.

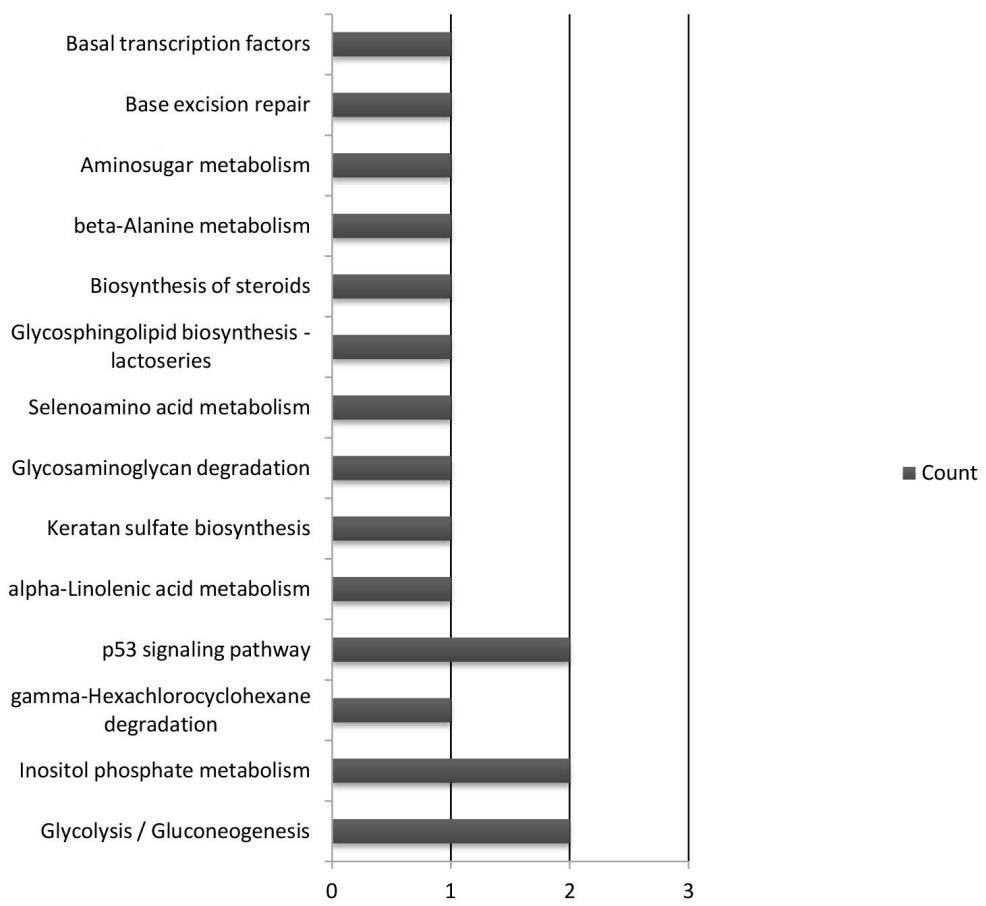

Figure 5. Pathway of differentially expressed genes in broilers fed orangeII. Count is the number of genes in a single pathway. 


\section{GO term analysis of differentially expressed genes}

The biological processes of differentially expressed genes were analyzed by MAS 3.0. The results of the GO terms showed that the differentially expressed genes of canthaxanthin broilers were mainly involved in regulation of transcription and DNA-dependent metabolism, development, transport, immune response, cell adhesion, calcium ion transport, lipid metabolism, skeleton development, skeleton muscle fiber development, catabolism, and pigmentation (Figure 6). The differentially expressed genes of natural lutein broilers were mainly involved in protein and amino acid phosphorylation, signal transduction, development, proteolysis, and carbohydrate metabolism (Figure 7). The differentially expressed genes of orange II broilers were involved in the regulation of calcium ion transport and smooth muscle contractions, pigmentation during development, hormone metabolism, immune system development, and cellular metabolism (Figure 8).

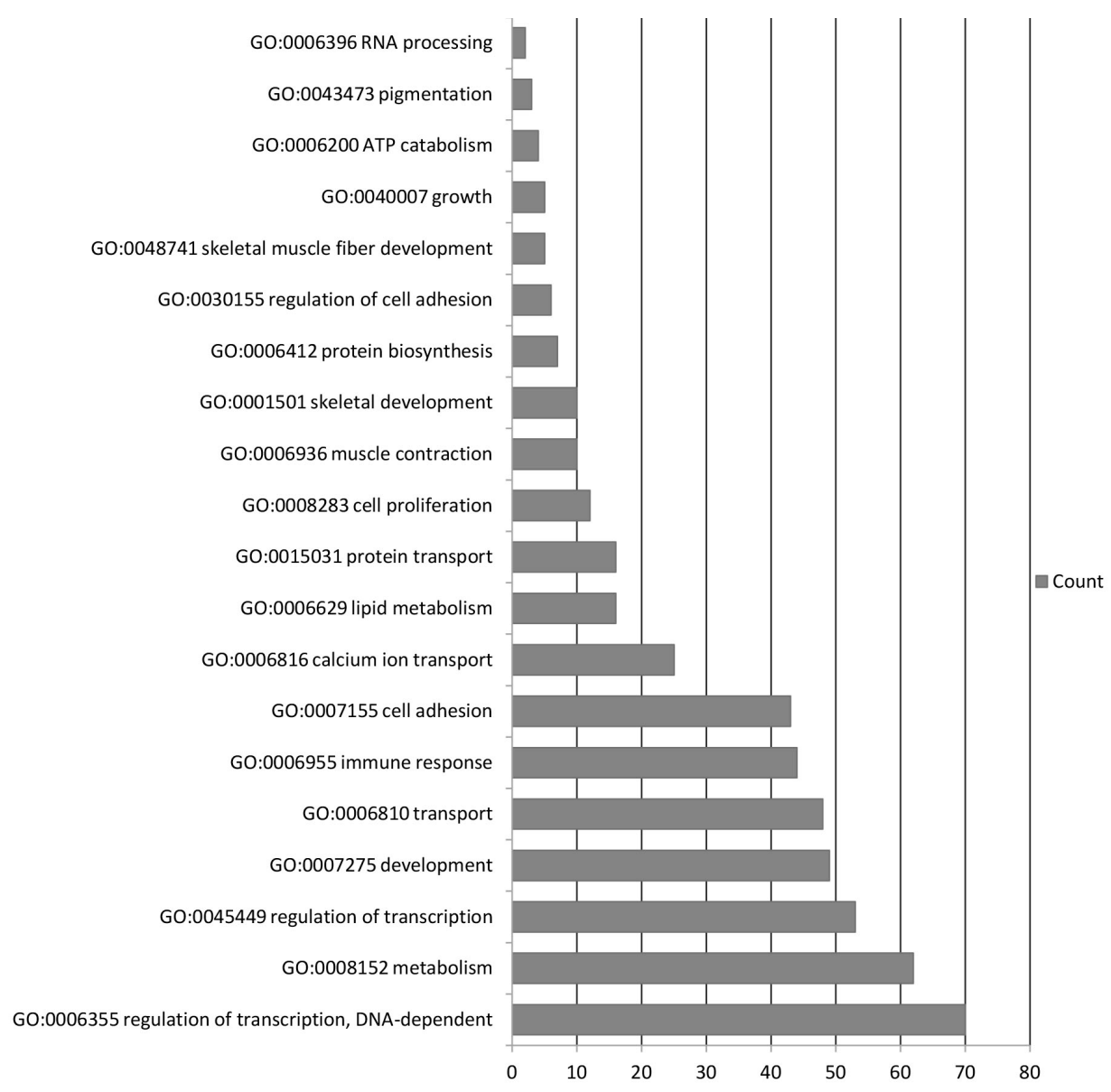

Figure 6. Gene Ontology analysis of differentially expressed genes in broilers fed canthaxanthin. Count is the number of genes in a single pathway. 
T.M. Tarique et al.

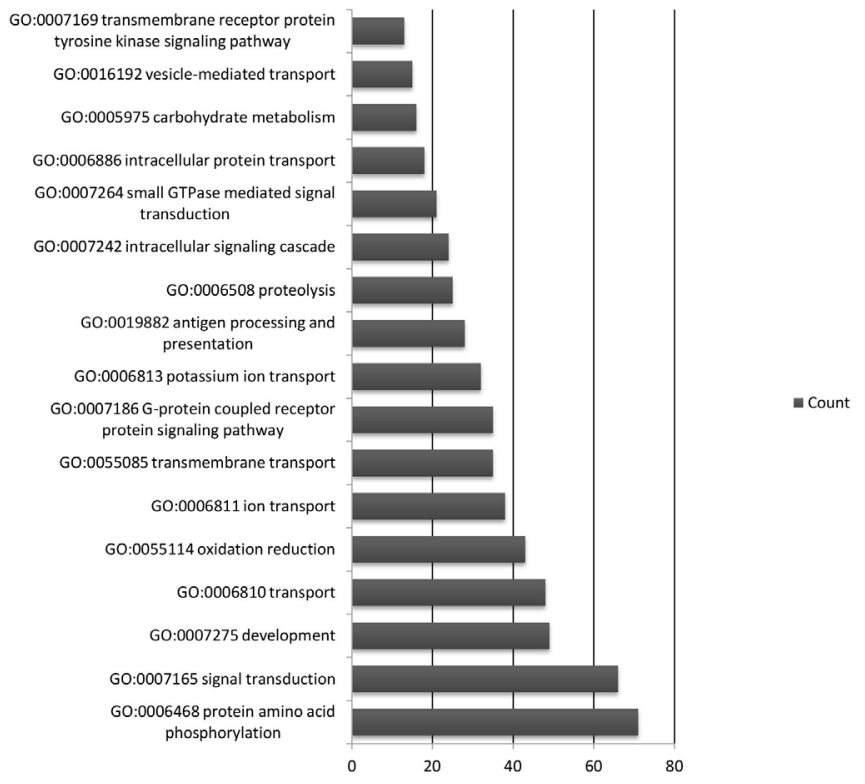

Figure 7. Gene Ontology analysis of differentially expressed genes in broilers fed natural lutein. Count is the number of genes in a single pathway.

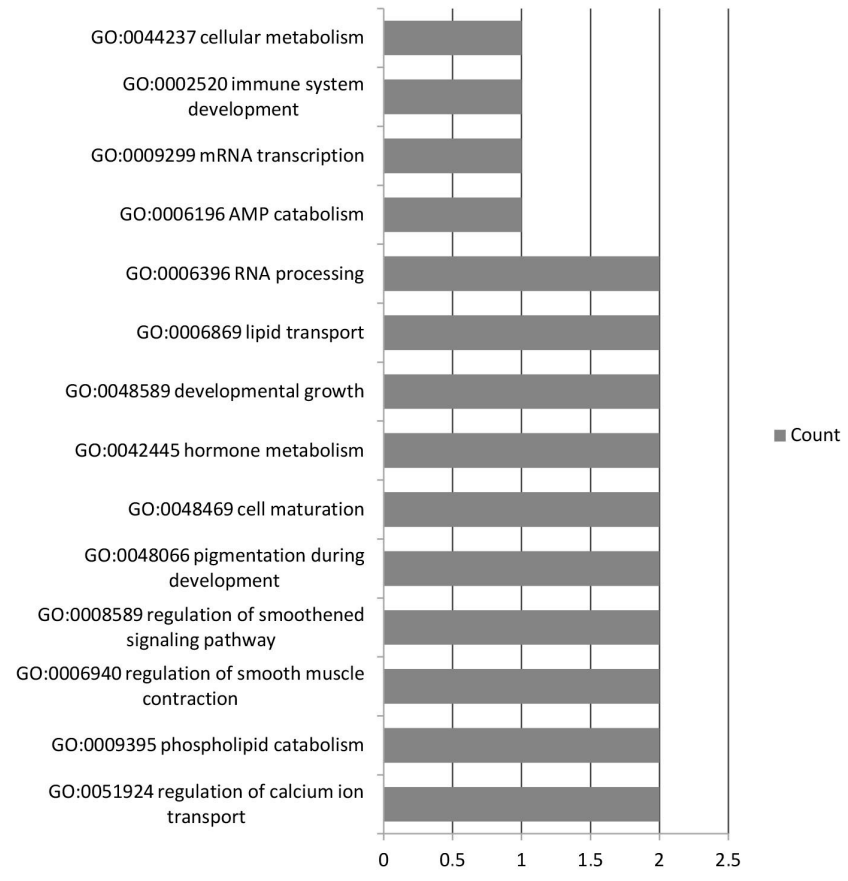

Figure 8. Gene Ontology analysis of differentially expressed genes in orangeII. Count is the number of genes in a single pathway. 
Gene regulation of pigments in broilers

\section{DISCUSSION}

Pigmentation promotes several advantages in broiler production, although the functions of pigments are also involved in growth metabolism and fertility (Scheldt, 1998). Various carotenoids act as precursors for the synthesis of vitamin A (Surai and Speake, 1998), while others provide protection to the body and act as physiological antioxidants (Burton, 1989), thus enhancing the immune system (Bendich, 1989; Blanch, 1999). However, current studies are underway to investigate gene expression profiles focusing on the different types of pigments associated with up- and downregulated genes. Three pigments were analyzed in the current experiment. A cluster analysis of breast muscle samples for birds fed $100 \mathrm{mg} / \mathrm{kg}$ canthaxanthin, natural lutein, or orangeII pigments at 7 weeks of age revealed differential gene expression among all the treated vs control broilers (Figure 1). A cluster analysis was applied to the normalized dataset to identify clusters among the treated $v s$ control samples. As expected, the dendrogram clearly separated the 3 nutritional conditions. Tamayo et al. (1999) showed that a particular group (cluster 11) of 46 genes exhibited higher levels of expression in embryos, and another group (cluster 3) of 21 genes exhibited higher levels of expression in hatchings. On the other hand, Törönen et al. (1999) showed that cluster 3 contained several genes that exhibited higher expression levels after incubation (i.e., at 1-10 days of age). Thus, the cluster analysis in the present study on chickens indicated different patterns of gene expression in the number of up- and downregulated genes for broilers fed $100 \mathrm{mg} / \mathrm{kg}$ canthaxanthin, natural lutein, or orangeII at 7 weeks of age.

Pigment deposition in chickens takes place mostly in the visceral adipose tissue, skin, and breast muscles. Even though many global surveys have been performed for the visceral tissues (Wang et al., 2007), this study is the first to examine gene expression profiles in breast tissue using 3 individual pigments in broiler diets. The data obtained here indicate that the differentially expressed genes are associated with broiler muscles (Tables 2 and 3), although some important genes involved in the regulatory mechanism of pigments were common among the treatment groups, and many other genes, most in fact, were not differentially expressed between the groups. The magnitude of the difference between the treatment groups was large; hence, significant differences in expression levels were clear. However, this is not uncommon. The other two studies that assessed the effects of supplementary carotenoids in feed additives and probiotics identified similarly large differences in the levels of gene expression. After administration of the different colored suspensions (Shima et al., 2008) for a comparison of differences in gene expression in the gastrointestinal tract of mice, 2- to 3 - fold differences were observed between significantly different genes (Brisbin et al., 2008); with the use of primary mononuclear cells from chickens incubated with cellular components of Lactobacillus acidophilus, a maximum 1.2-fold difference in significantly different genes was observed. Haghighi et al. (2008) evaluated the gene expression of selected genes in chicks treated with color dye on the day of hatching and challenged with Salmonella enterica serovar Typhimurium (ST) at $24 \mathrm{~h}$ post treatment. Gene expression, which was evaluated in the cecal tonsils, a lymphoid tissue at the ileocecal junction, exhibited an increase in interleukin 12 in response to ST that was maintained at control levels at 1 and 5 days after challenge. Haghighi et al. (2008) also observed that ST increased interferon gamma (IFN $\gamma$ ) on day 5; however, color-dye-treated chicks showed reduced levels of IFN $\gamma$. Jolly et al. (2005) concluded via comparison of pooled $v s$ individual sample microarray analyses that the two 
approaches for running microarray chips were comparable; however, the individual analysis revealed subtle changes that affected interpretation of the experiment that were not identified using the pooled analysis, which were important for elucidating the target mechanisms. However, Kendziorski et al. (2005) indicated that pooling samples for microarray analysis minimizes the variation from subject-to-subject that "is often desirable when primary interest is not on the individual but rather on characteristics of the population from which certain individuals are obtained (e.g., identifying biomarkers or expression patterns common across individuals)". Likewise, in the context of the present study, we were more interested in the investigation of the expression profile of genes between individuals with high and low feed efficiencies according to Kendziorski et al. (2005) at the potential expense of losing some mechanistic understanding, as shown by Jolly et al. (2005). In this regard, Kong et al. (2011) reported that, based on the differentially expressed genes, the high feed efficiency appeared to be the product of the upregulation of genes associated primarily with anabolic processes, whereas the low feed efficiency broiler breast muscle phenotype exhibited upregulation of genes associated with muscle fiber development, muscle function, cytoskeletal organization, and stress response. As discussed, based on our array data, we found that the expression ratio between the treatments was different with regard to the pectoralis major muscles of broilers in the present study. The up- and downregulated genes in birds fed $100 \mathrm{mg} / \mathrm{kg}$ canthaxanthin exhibited 2.1- to 323.9204-fold and 0.112- to 0.480-fold differences in gene expression, respectively; the up- and downregulated genes in birds fed natural lutein exhibited 2.132- to 8.362-fold and 0.37- to 0.48-fold differences in gene expression, respectively. While the upand downregulated genes in birds fed orangeII exhibited 2.00- to 6.87-fold and 0.135- to 0.359 -fold differences in gene expression, respectively. Significant differences in the up- and downregulation of differentially expressed genes in canthaxanthin-fed animals were observed throughout the experiment when compared to those in the other treatments. One possible reason for this finding is that the canthaxanthin pigment may experience an increased absorption rate. Nevertheless, to date, studies have not illustrated the regulatory mechanism underlying pigmentation.

The regulatory mechanism underlying broiler pigmentation requires accurate coordination of many genes. As shown, the various pathways could be involved in this regulatory mechanism. In order to explore possible key regulators, we mapped $D E$ gene pathways, as shown with regard to: 1) canthaxanthin (Figure 3), including the calcium signal pathway, drug metabolism, caffeine metabolism, purine metabolism, retinol metabolism, and MAPK signaling pathway; 2) natural lutein (Figure 4), including riboflavin metabolism, methionine metabolism, vitamin B6 metabolism, apoptosis, fatty acid metabolism, and thiamine metabolism; and 3) orangeII (Figure 5), including glycolysis/gluconeogenesis, keratan sulfate biosynthesis, and steroid biosynthesis. Interestingly, a number of cofactor and vitamin metabolism pathways were enriched with $D E$ genes, including vitamin B6, thiamine metabolism, and riboflavin metabolism pathways, which suggest that vitamin-correlated nutritional metabolism, might be involved in broiler pigmentation.

The GO term analysis results showed that only a few biological processes such as pigmentation, skeletal development, transport, and iron transport and development were enriched via the canthaxanthin, natural lutein, and orangeII treatments (Figure 6-8), suggesting that they might contribute to the mechanism of pigmentation. Several other genes that exhibited expression profiles that correlated well with the mechanism of pigmentation in broilers are 
also shown in Tables 2 and 3. A large number of differentially expressed genes were identified in the broilers fed the canthaxanthin pigment when compared to that in the other treatments. Of note, the GO and KEGG analyses provided the first demonstration that a series of pathway GO terms related to pigmentation are important for elucidating the genes involved in the regulatory mechanism of pigmentation in broilers. Unfortunately, it was not possible to provide additional evidence with regard to this mechanism based on the molecular study of pigments because none of the identified gene expression profiles were related to pigmentation in broilers.

\section{CONCLUSION}

The results of this study identified potential candidate genes involved in the regulatory mechanism of pigments in broiler chickens, focusing on the top up- and downregulated genes associated with pigmentation and pathways; broilers were fed $100 \mathrm{mg} / \mathrm{kg}$ canthaxanthin, natural lutein, and orangeII diets. In conclusion, our microarray data established the ground work and provide a dynamic view for understanding the molecular mechanism underlying pigmentation in broilers. In the future, studies on gene expression will further contribute to our understanding of the molecular mechanism of pigmentation and the potential applications for broiler production.

\section{Conflicts of interest}

The authors declare no conflict of intrests

\section{ACKNOWLEDGMENTS}

Research supported by the Special Funds for Agro-scientific Research in the Public Interest (\#201203023, \#201203046)

\section{REFERENCES}

Bendich A (1989). Carotenoids and the immune response. J. Nutr. 119: 112-115.

Blanch A (1999). Getting the color of yolk and skin right. World's Poult. Sci. J. 15: 32-33.

Brisbin JT, Zhou H, Gong J, Babour P, et al. (2008). Gene expression profiling of chicken lymphoid cells after treatment with Lactobacillus acidophilus cellular components. Dev. Comp. Immunol. 32: 563-574.

Burton GW (1989). Antioxidant action of carotenoids. J. Nutr. 119: 109-111.

Castañeda MP, Hirschler EM and Sams AR (2005). Skin pigmentation evaluation in broilers fed natural and synthetic pigments. Poult. Sci. 84: 143-147.

Cogburn LA, Wang X, Carre W, Rejto L, et al. (2003). Systems-wide chicken DNA microarrays, gene expression profiling, and discovery of functional genes. Poult. Sci. 82: 939-951.

Fletcher DL (1999). Poultry Meat Color. In: Poultry meat science (Richardson RI and Mead GC,eds.). CAB International, Oxon, pp. 159-174.

Haghighi HR, Abdul-Careem MF, Dara RA, Chambers JR, et al. (2008). Cytokine gene expression in chicken cecal tonsils following treatment with probiotics and Salmonella infection. Vet. Microbiol. 126: 225-233.

Jolly RA, Goldstein KM, Wei T, Gao H, et al. (2005). Pooling samples within microarray studies: A comparative analysis of rat liver transcription response to prototypical toxicants. Physiol. Genomics 22: 346-355.

Kendziorski CM, Zhang Y, Lan H and Attie AD (2003). The efficiency of pooling mRNA in microarray experiments. Biostatistics 4: 465-477.

Kendziorski C, Irizarry RA, Chen KS, Haag JD, et al. (2005). On the utility of pooling biological samples in microarray 
experiments. Proc. Natl. Acad. Sci. U. S. A. 102: 4252-4257.

Kong BW, Song JJ, Lee JY, Hargis BM, et al. (2011). Gene expression in breast muscle associated with feed efficiency in a single male broiler line using a chicken $44 \mathrm{~K}$ oligo microarray I. Top differentially expressed genes. Poult. Sci. 90: 2535-2547.

Li X, Chiang HI, Zhu J, Dow SE, et al. (2008). Characterization of a newly developed chicken 44K Agilent microarray. BMC Genom. 9:60.

Nakachi Y, Yagi K, Nikaido I, Bono H, et al. (2008). Identification of novel PPARgamma target genes by integrated analysis of ChIP-on-chip and microarray expression data during adipocyte differentiation. Biochem. Biophys. Res. Commun. 372: 362-366.

National Research Council (1994) Nutrient requirements of poultry. The National Academic Press, Washington, DC.

Scheldt K (1998). Absorption and metabolism of carotenoids in birds, fish and crustaceans. In: Biosynthesis and metabolism (Britton G, Liaaen Jensen and Pfander H, eds.). Birkhauser, Verlag, pp. 285-358.

Shima T, Fukushima K, Setoyama H, Imaoka A, et al. (2008). Differential effects of two probiotic strains with different bacteriological properties on intestinal gene expression, with special reference to indigenous bacteria. FEMS Immunol. Med. Microbiol. 52: 69-77.

Sunde ML (1992). The scientific way to pigment poultry products. Introduction to the symposium. Poult. Sci. 71: 709-710.

Surai PF and Speake BK (1998). Distribution of carotenoids from the yolk to the tissues of the chick embryo. J. Nutr. Biochem. 9: 645-651.

Tamayo P, Slonim D, Mesirov J, Zhu Q, et al. (1999). Interpreting patterns of gene expression with self-organizing maps: methods and application to hematopoietic differentiation. Proc. Natl. Acad. Sci. U. S. A. 96: 2907-2912.

Tarique TM, Yang S, Mohsina Z, Qiu J, et al. (2013). Role of carotenoids in poultry industry in China: a view. J. Nat. Sci. Res. 3: 111-121.

Törönen P, Kolehmainen M, Wong G and Castrén E (1999). Analysis of gene expression data using self-organizing maps. FEBS Lett. 451:142-146.

Tyczkowski JK and Hamilton PB (1986). Lutein as model dihydroxycarotenoid for the study of pigmentation in chickens. Poult. Sci. 65: 1141-1145.

van Hal NL, Vorst O and van Houwelingen AM (2000). The application of DNA microarrays in gene expression analysis. J. Biotechnol. 78: 271-280.

Wallis JW, Aerts J, Groenen MA, Crooijmans RP, et al. (2004). A physical map of the chicken genome. Nature 432: 761-764.

Wang HB, Li H, Wang QG, Zhang XY, et al. (2007). Profiling of chicken adipose tissue gene expression by genome array. BMC Genomics 27: 193-207.

Wong GK, Liu B, Wang J, Zhang Y, et al. (2004). A genetic variation map for chicken with 2.8 million single-nucleotide polymorphisms. Nature 432: 717-722. 